OPEN ACCESS

Check for updates

\title{
Term complications and subsequent risk of preterm birth: registry based study
}

\author{
Liv G Kvalvik, ${ }^{1,2}$ Allen J Wilcox, ${ }^{3}$ Rolv Skjærven, ${ }^{1,4}$ Truls $\varnothing$ stbye, ${ }^{5}$ Quaker E Harmon ${ }^{3}$
}

${ }^{1}$ Department of Global Public Health and Primary Care, University of Bergen, Postbox 7804, N-5020 Bergen, Norway ${ }^{2}$ Department of Biomedicine, University of Bergen, Bergen, Norway

${ }^{3}$ National Institute of

Environmental Health Sciences,

Durham, NC, USA

${ }^{4}$ Centre for Fertility and Health, Norwegian Institute of Public Health, Oslo, Norway

${ }^{5}$ Department of Family Medicine and Community Health, Duke

University, Durham, NC, USA

Correspondence to:L G Kvalvik Liv.Kvalvik@uib.no

(or@livlivonlineno1 on Twitter; ORCID 0000-0001-6520-9057)

Additional material is published online only. To view please visit the journal online.

Cite this as: BM/2020;369:m1007 http://dx.doi.org/10.1136 bmj.m1007 Accepted: 5 March 2020

\section{ABSTRACT}

OBJECTIVE

To explore conditions and outcomes of a first delivery at term that might predict later preterm birth.

\section{DESIGN}

Population based, prospective register based study.

SETTING

Medical Birth Registry of Norway, 1999-2015.

\section{PARTICIPANTS}

302192 women giving birth (live or stillbirth) to a second singleton child between 1999 and 2015.

\section{MAIN OUTCOME MEASURES}

Main outcome was the relative risk of preterm delivery ( $\$ 37$ gestational weeks) in the birth after a term first birth with pregnancy complications: pre-eclampsia, placental abruption, stillbirth, neonatal death, and small for gestational age.

\section{RESULTS}

Women with any of the five complications at term showed a substantially increased risk of preterm delivery in the next pregnancy. The absolute risks for preterm delivery in a second pregnancy were $3.1 \%$ with none of the five term complications (8202/265 043), 6.1\% after term pre-eclampsia (688/11 225), 7.3\% after term placental abruption (41/562), 13.1\% after term stillbirth (72/551), $10.0 \%$ after term neonatal death (22/219), and $6.7 \%$ after term small for gestational age (463/6939). The unadjusted relative risk for preterm birth after term pre-eclampsia was 2.0 (95\% confidence interval 1.8 to 2.1$)$, after term placental abruption was 2.3 (1.7 to 3.1), after term stillbirth was 4.2 (3.4 to 5.2), after term neonatal death was 3.2 (2.2 to 4.8), and after term small for gestational age was 2.2 (2.0 to 2.4). On average, the risk of preterm birth was increased 2.0fold (1.9-fold to 2.1 -fold) with one term complication in the first pregnancy, and 3.5-fold (2.9-fold to 4.2fold) with two or more complications. The associations

\section{WHAT IS ALREADY KNOWN ON THIS TOPIC}

Preterm delivery is an important predictor of future preterm delivery

Generally, women who deliver at term have low risk of preterm delivery in later pregnancies

\section{WHAT THIS STUDY ADDS}

A subset of women who deliver at term with specific complications are at substantially increased risk of subsequent preterm delivery

The link between term complications including pre-eclampsia, placental abruption, stillbirth, neonatal death, and small for gestational age infants, and preterm delivery implies shared underlying causal factors

These findings can help identify women at increased risk of preterm delivery despite having had a previous term birth

persisted after excluding recurrence of the specific complication in the second pregnancy. These links between term complications and preterm delivery were also seen in the reverse direction: preterm birth in the first pregnancy predicted complications in second pregnancies delivered at term.

\section{CONCLUSIONS}

Pre-eclampsia, placental abruption, stillbirth, neonatal death, or small for gestational age experienced in a first term pregnancy are associated with a substantially increased risk of subsequent preterm delivery. Term complications seem to share important underlying causes with preterm delivery that persist from pregnancy to pregnancy, perhaps related to a mother's predisposition to disorders of placental function.

\section{Introduction}

Women with a pregnancy at term are generally considered to be at reduced risk for subsequent preterm birth, whereas a previous preterm birth is a major predictor of a future one. ${ }^{12}$ The strong risk of recurrent preterm birth suggests persistent causal factors in the mother or her environment. These factors could act through disorders of placental function, which are often found in preterm birth and can also contribute to other complications such as preeclampsia and placental abruption in both term and preterm pregnancies. $^{3}$

Preterm birth-especially before 34 weeks-is more than the simple onset of labour. Underlying conditions almost certainly play a role. ${ }^{3}$ These conditions might act on the fetus and mother for weeks or months before delivery. This idea is supported by the observation that fetuses born preterm are smaller than those of the same gestational age who continue in utero. ${ }^{45}$ The term "great obstetrical syndromes" is intended to call attention to the possibility of shared pathways linking pregnancy conditions and outcomes such as pre-eclampsia, placental abruption, poor fetal growth, and fetal death. ${ }^{6-8}$ Some authors have suggested that these various conditions and outcomes could all be considered as manifestations of dysfunctional placental function (ischaemic placental disease), rather than distinct entities. ${ }^{9-11}$ The associations among these conditions have been identified mainly when they occur in preterm births. ${ }^{11-15}$

The possible relation between obstetrical complications or poor infant outcomes at term and later preterm birth has been less closely studied. Clinical guidelines for identifying pregnancies at risk of preterm birth do not mention previous complications in a term first pregnancy as a risk factor. ${ }^{16-19}$ We explore the possibility that underlying pathologic mechanisms 
might link conditions occurring in term pregnancies with later preterm birth.

We used the population based registries of Norway to explore whether pregnancy complications or poor outcomes at term (pre-eclampsia, placental abruption, stillbirth and neonatal death, and poor fetal growth) might increase the risk of preterm birth in a subsequent pregnancy.

\section{Methods}

Data sources

We obtained the main data from the population based Medical Birth Registry of Norway. Since 1967, the registry has collected data on all births after 16 weeks of gestation. ${ }^{20}$ Data collected includes demographic, medical and reproductive history, lifestyle, prepregnancy and prenatal information transferred from the antenatal chart, complications during pregnancy and delivery, and fetal and infant outcomes. The birth registry notification form was revised in 1998 to include information on smoking, HELLP (haemolysis, elevated liver enzymes and low platelets) syndrome, and ultrasound based gestational age. We restricted analysis to a woman's first and second deliveries (live births and stillbirths), which were linked using the maternal identification number. Information on maternal education were obtained from Statistics Norway.

\section{Study cohort and demographic variables}

The main study cohort consisted of 302192 women giving birth (live birth or stillbirth) to a second singleton child between 1999 and 2015. We focused on this most recent period because it reflects current clinical practice. We also conducted secondary analyses of births from the complete available registry period (1967-2015).

Women with information missing on gestational age $(3.0 \%)$ or birth weight $(0.2 \%)$, or with gestational age outside the range of 20-46 weeks $(0.5 \%)$ were excluded. To eliminate unlikely gestational age and birthweight combinations, we further excluded women with babies who weighed more than 5 standard deviations above the mean for gestational week of birth $(0.1 \%) .^{21}$ The final eligible study population was 302192 women. The primary analysis focused on women with a term first birth $(\mathrm{n}=284225)$.

\section{Outcomes and exposures}

Our main outcome was preterm birth in the second delivery, defined as a liveborn or stillborn infant delivered at 20 to 36 gestational weeks. Gestational age was defined as completed weeks and is based on the date of the last menstrual period. Exceptions were those with missing information on last menstrual period or for which the last menstrual period differed from the ultrasound result by more than 10 days, in which case we used the ultrasound result, or for pregnancies conceived by in vitro fertilisation for which we used the date of embryo transfer plus 14 days.
We identified five complications or poor outcomes of term pregnancy for analysis: pre-eclampsia, placental abruption, stillbirth, neonatal death, and small for gestational age. For the sake of simplicity, we refer to these collectively as "complications." The causes of these complications are complex and include placental dysfunction. ${ }^{368922}$ As with preterm birth, these complications all tend to recur in subsequent pregnancies. ${ }^{23-26}$ We included neonatal deaths (in the first 28 days of life) because infants who die shortly after birth are likely to include those exposed to placental dysfunction. To exclude most constitutionally small infants, we used a strict centile for small for gestational age (parity specific birthweight below the 2.5 th centile at each term gestational week, grouping births at weeks 44 and later).

Before 1999, pre-eclampsia, eclampsia, and placental abruption had been recorded in the medical birth registry as free text. From 1999, check boxes for these outcomes were added to the registry forms, which improved data quality. The pre-eclampsia outcome includes pregnancies with pre-eclampsia, HELLP syndrome, or eclampsia, as well as chronic hypertension with superimposed pre-eclampsia. A validation study of pre-eclampsia diagnosis as recorded in the birth registry (1999-2010), found a satisfactory positive predictive value (84\%) and high specificity (99\%) but low sensitivity (43\%)-that is, the registry misclassifies a substantial number of cases (mostly mild) as non-cases. ${ }^{27}$ All cases of eclampsia since 1999 are verified by hospitals.

Owing to registry coding routines, 2015 data for pre-eclampsia, placental abruption, and initiation of delivery (spontaneous, indicated, caesarean section) were incomplete in the dataset available for analysis. Analyses are therefore restricted to 1999-2014 for those three variables.

\section{Statistical analysis \\ Primary analysis}

We used log binomial regression to calculate relative risks with 95\% confidence intervals for the association between term complications in first pregnancies and risk of preterm birth in second pregnancies. Separate models were used for each term complication. The reference for each model was first pregnancies at term with none of the five complications. Our focus is on prediction, in the same way that preterm delivery in the first pregnancy is an important predictor of later preterm birth. For this reason, we present unadjusted relative risks as the main finding, without adjustment for possible shared causal factors that might contribute to predictive power. In additional analysis, we adjusted for known demographic and lifestyle factors that might contribute to the observed associations.

\section{Co-occurrence of complications and recurrence of complications}

These term complications might co-occur in a given pregnancy. We therefore ran an additional model estimating the associations between having any one 
complication, or any two or more complications, and the subsequent risk of preterm birth. Despite population level data being available for more than a decade, numbers were too small to consider unique combinations of complications. We therefore modelled the variables no complication, any one complication, and any two or more complications in a single model.

A complication of term pregnancy might contribute to a future preterm birth if the same complication recurred before term in the next pregnancy. To remove the influence of such recurrences, we reanalysed our data after excluding second pregnancies with the same complication as the first.

\section{Role of clinical intervention}

A previous complication at term might also increase preterm birth by prompting clinicians to deliver babies shortly before term to avoid recurrence of the same term outcome. To the extent this occurs, we would expect an excess of preterm births to occur in the later preterm weeks (weeks 34-36). We therefore assessed the risk of delivery across the full range of gestational weeks, using all pregnancies in utero at the beginning of each week interval as the denominator (a fetuses at risk approach). Specifically, the risk of birth in a given gestational week interval (20-24, 25-27, 28-30, 31-33, $34-36,37-38,39-40$, and 41-42 weeks) was expressed as births occurring in the given interval divided by all fetuses in utero at the beginning of that interval.

Clinical intervention resulting in preterm birth in the second pregnancy might also be suggested if estimates differed between spontaneous and induced preterm births. We examined the associations within mutually exclusive stratums of preterm birth that capture the initiation of labour: spontaneous or iatrogenic (including induced labour and caesarean section). Caesarean section in this context captures only deliveries where the procedure was performed before the spontaneous or medically induced onset of labour.

\section{Secondary analysis}

We conducted a series of secondary analyses to identify possible explanatory factors and vulnerable subpopulations.

\section{Adjustment for known shared risk factors}

Known demographic or behavioural risk factors might contribute to the associations. These risk factors included maternal age, smoking, education, country of birth; year of delivery; and prepregnancy body mass index (BMI). We adjusted for known risk factors at the time of the first pregnancy to avoid introducing bias from factors that might have changed as a result of a poor outcome in the first pregnancy. Information on smoking and BMI was available for the more recent subset of data (smoking in births occurring in 1999-2015 and BMI in births occurring in 200615). Smoking behaviour at the end of pregnancy was dichotomised into non-smoking (reference) and any smoking (occasional and daily smoking). Adjustment for smoking excluded 48914 women (21\%) with missing data.

Weight and height have been registered through an electronic birth notification system that the birth registry has gradually adopted since 2006, and which was not complete until 2014. The proportion of women with registered height and weight increased from $0.1 \%$ in 2006 to $72 \%$ in $2014 .{ }^{28}$ For our analysis, we divided prepregnancy BMI into three categories: 15-24.9 (reference), 25-29.9, and 30 or more. Owing to the gradual uptake of BMI registration, 70\% $(n=83574)$ of women with first pregnancies in 2006-15 were missing information on prepregnancy BMI in the first pregnancy and were excluded from the analyses adjusting for BMI.

Year of first birth was treated as an indicator variable, with 1974 (the earliest first delivery in our analytical subset) as the reference. Maternal education level was divided into less than 11 years and 11 years or more (reference). In Norway, 11 years of education is equivalent to high school or secondary school. Maternal country of birth was categorised as Nordic or non-Nordic.

\section{"Reverse" analysis}

An observed association between term complications in a first pregnancy and subsequent preterm birth could be due to shared causal factors. A less likely possibility is that such associations could be caused by physiological damage to the maternal reproductive system from the earlier complication. If this were true, we would not expect associations to hold in the reverse direction-preterm birth in the first pregnancy should not increase the risk of term complications in the next pregnancy. We therefore assessed preterm birth in the first pregnancy as a risk factor for term complications in the second pregnancy, excluding women with the specific condition in the first pregnancy. We first considered preterm birth in all weeks as a single group and then dichotomised into early preterm (20-33 weeks) and late preterm (34-36 weeks). Outcomes in this "reverse" analysis were the same five complications (term pre-eclampsia, placental abruption, stillbirth, neonatal death, and small for gestational age), now in second pregnancies. The denominator for neonatal mortality in second pregnancies was restricted to live births. All analyses used first pregnancies ending in term delivery as the reference group. The reference further excluded women with the complication of interest in the second pregnancy.

\section{Changes over time and change in partner and interpregnancy interval}

To assess the possible impact of changes in clinical practice over time, we repeated the primary analysis for each of three periods (second births in 1967-82, 1983-98, and 1999-2015) and compared the strength of the associations over time.

To address a possible contribution of paternal factors, we conducted separate analyses stratified by whether women had the same partner or different 
partners for their two pregnancies. In additional analysis we adjusted for interpregnancy interval as an indicator variable categorised using centile cut points (10th, 25th, 50th, 75th, and 90th centile) of the months between first birth and second conception.

\section{Restricting to a narrow definition of term births in first pregnancy}

Finally, we repeated the main analysis restricting to first term births at weeks 39-41. This excluded early term births (which may share features with preterm births) and post-term births. The supplementary tables provide further descriptions of these secondary analyses together with results. Analyses were conducted in STATA version 15.0 (College Station, TX).

\section{Patient and public involvement}

Patients, families, or the public were not involved in the design, choice of outcome measures, or interpretation of results in the current study.

\section{Results}

In total, 302192 women had a second birth in 19992015 (fig 1). Table 1 provides a description of this sample. The overall risk of preterm birth in the first pregnancy was 5.9\% (17967/302 192). Among women with term births in their first pregnancy, $4.2 \%(11225 / 266380)$ had pre-eclampsia, $0.2 \%$
(562/266380) had placental abruption, 0.2\% (551/284225) had stillbirth, $0.1 \%$ had a neonatal death (219/284 225), and 2.4\% (6939/284 220) had a small for gestational age infant (table 1).

The risk of recurrence of preterm birth in the second pregnancy was $18.1 \%(3257 / 17967)$, with a relative risk of 5.5 (95\% confidence interval 5.3 to 5.7 ) compared with a term first birth. Although lower than the recurrence risk of preterm birth, each of the five complications of term pregnancy was associated with a substantially increased risk of preterm birth in the subsequent pregnancy (table 2, fig 2). The absolute risks for preterm birth in the second pregnancy were 3.1\% with none of the five complications (8202/265043), $6.1 \%$ after pre-eclampsia (688/11225), 7.3\% after placental abruption (41/562), 13.1\% after stillbirth (72/551), $10.0 \%$ after neonatal death (22/219), and $6.7 \%$ after small for gestational age (463/6939). The unadjusted relative risk of preterm birth after preeclampsia was 2.0 (95\% confidence interval 1.8 to 2.1 ), after placental abruption was 2.3 (1.7 to 3.1), after still birth was 4.2 (3.4 to 5.2), after neonatal death was 3.2 (2.2 to 4.8), and after small for gestational age was 2.2 (2.0 to 2.4) (table 2).

Compared with having none of the five complications in the first pregnancy, having any one of them was associated with a doubling in risk of a subsequent preterm birth (relative risk 2.0, 95\% confidence

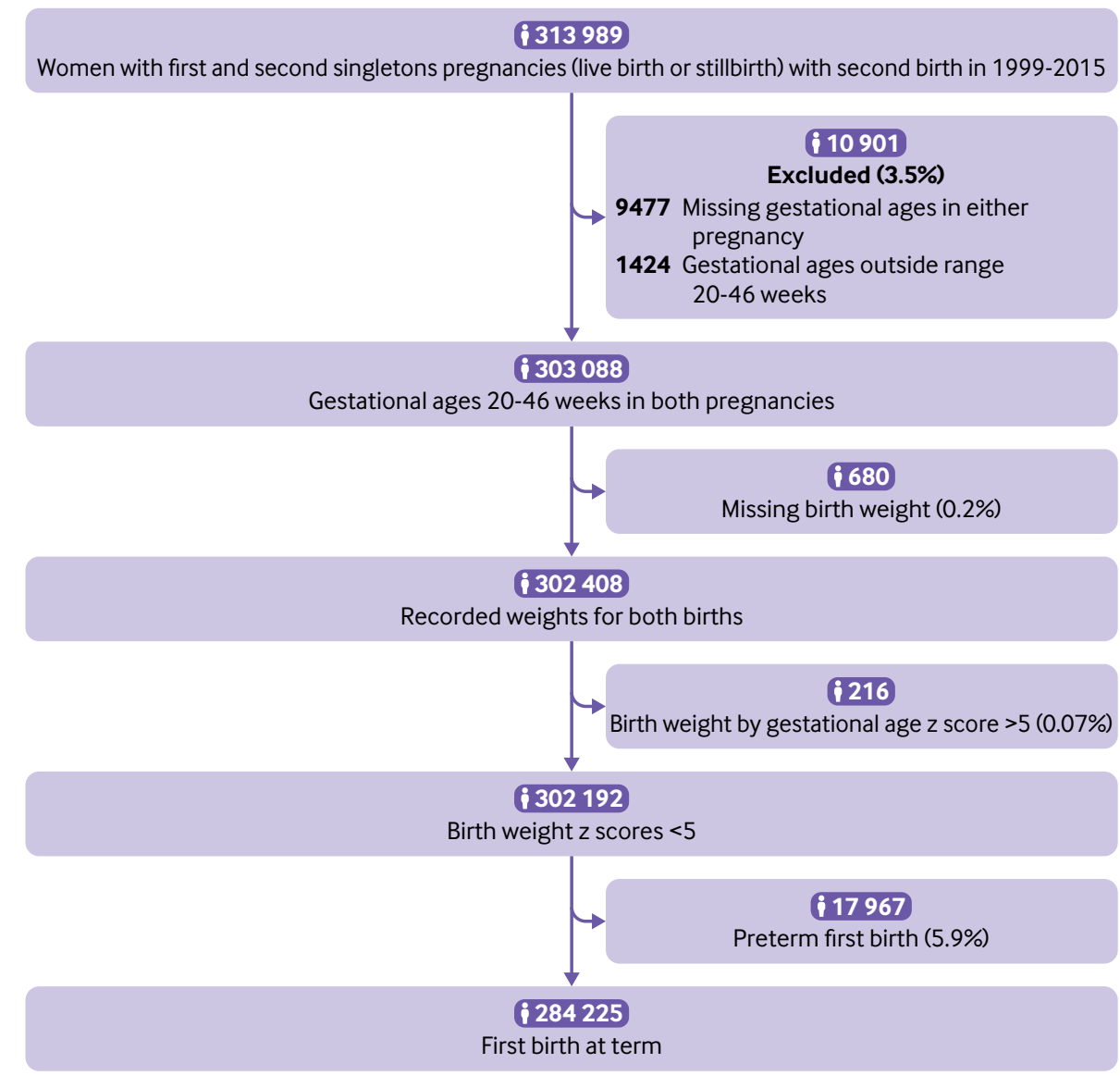

Fig 1 | Flowchart of study population 


\begin{tabular}{|c|c|}
\hline Characteristics & No (\%) \\
\hline Total No & $302192(100)$ \\
\hline \multicolumn{2}{|l|}{ Maternal age at first birth (years): } \\
\hline$<20$ & $17951(6)$ \\
\hline $20-24$ & $83810(28)$ \\
\hline $25-29$ & $122788(41)$ \\
\hline $30-34$ & $64394(21)$ \\
\hline$\geq 35$ & $13249(4)$ \\
\hline \multicolumn{2}{|l|}{ Maternal education (years): } \\
\hline$<11$ & $41551(14)$ \\
\hline$\geq 11$ & $254743(84)$ \\
\hline Unknown & $5898(2)$ \\
\hline Mother born in Nordic country* & $258868(86)$ \\
\hline \multicolumn{2}{|l|}{ Maternal smokingt: } \\
\hline No & $170426(72)$ \\
\hline Yes & $16458(7)$ \\
\hline Not registered & $48914(21)$ \\
\hline \multicolumn{2}{|l|}{ Maternal prepregnancy body mass index $\neq$ : } \\
\hline $15-24.9$ & $25293(21)$ \\
\hline 25.29 .9 & $7,287(6)$ \\
\hline$\geq 30$ & $3,633(3)$ \\
\hline Change in partner§ & $33574(11)$ \\
\hline \multicolumn{2}{|l|}{ Outcome in 1st pregnancy: } \\
\hline Preterm & $17967(5.9)$ \\
\hline Term & $284225(94.1)$ \\
\hline \multicolumn{2}{|c|}{ Outcome among women with term 1st pregnancy (No/No at risk (\%)): } \\
\hline Pre-eclampsiaף & $11225 / 266380(4.2)$ \\
\hline Placental abruption & $562 / 266380(0.2)$ \\
\hline Stillbirth & $551 / 284225(0.2)$ \\
\hline Neonatal death & $219 / 284225(0.1)$ \\
\hline Small for gestational age (2.5th centile) ${ }^{\star \star}$ & $6939 / 284220(2.4)$ \\
\hline \multicolumn{2}{|c|}{$\begin{array}{l}\text { *Include Norway, Denmark, Finland, Iceland, and Sweden. Information was missing for } 4070(1 \%) \text { women. } \\
\text { tFor supplemental analysis including smoking at end of first pregnancy as a covariate, women with smoking not } \\
\text { registered }(\mathrm{n}=48914 / 235798(21 \%) \text { ) were excluded from analysis. As smoking was first recorded from } 1999 \text {, } \\
\text { these analyses include only women whose first births were from } 1999(\mathrm{n}=235798) \text {. } \\
\text { \#For sensitivity analysis on prepregnancy, body mass index data are only available incrementally from maternity } \\
\text { units from } 2006 \text { to } 2015 \text {. In this period, data were missing for } 83574 / 119787(70 \%) \text { women. } \\
\$ 296659 \text { women had an identified partner in both pregnancies. } \\
\text { qFor analysis, the period is restricted to } 1999-2014(\mathrm{n}=266380) \text {, as reflected by the percentage. } \\
\text { **To avoid the possibility of data entry issues, term births with birth weight fewer than three digits }(\leq 999 \mathrm{~g}) \text { were } \\
\text { excluded from the small for gestational age analysis }(n=5) \text {. }\end{array}$} \\
\hline
\end{tabular}

interval 1.9 to 2.1) (absolute risk 6.2\%), whereas the relative risk with two or more complications was 3.5 (2.9 to 4.2) (absolute risk 10.9\%).

When recurrences of a specific complication in the second birth were excluded, the relative risks of preterm birth were largely unchanged. The exception was for risk after pre-eclampsia, which decreased from 2.0 to 1.4 (1.3 to 1.6 ) (table 2 ).

\section{Adjusting for known shared risk factors}

The associations were slightly attenuated after adjusting for maternal age, education, and year of birth except for risk after pre-eclampsia and stillbirth in the first pregnancy, which remained unchanged (fig 2). After further adjustment for smoking (restricted to both births occurring during 1999-2015) and maternal country of birth the findings were similar to unadjusted results during the same period. Results were also similar after adding pre-pregnancy BMI from the first pregnancy to the adjustment variables and restricting the dataset to those women with recorded BMI (supplementary eTable 1).

\section{Role of clinical intervention}

The relative risk of a preterm birth in a second pregnancy after complications in a first pregnancy at term was increased in nearly every preterm interval, with no evidence of a concentration of risk among the late preterm or early term weeks (fig 3, and supplementary eTable 2 and eTables $3 a-3 b)$. On the contrary, the relative risks of delivery after a term complication were highest early in the next pregnancy, in weeks 28-30.

Medical intervention in the second pregnancy does not appear to account for the observed associations. All modes of delivery initiation were associated with increased risks for preterm birth after term complications, with the highest risks generally observed for spontaneous preterm birth (supplementary eTable 4).

\section{Secondary analyses \\ Reverse association}

The associations between term complications and subsequent preterm birth suggest shared underlying causes. If so, the associations would be expected to hold in the other direction as well: preterm birth should increase the risk of complications in a subsequent term pregnancy. This was confirmed (table 3). Women whose first pregnancy ended in preterm birth had a generally increased risk of term complications in their second pregnancy, with the strongest associations after early preterm birth (20-33 weeks).

\section{Periods of second birth}

In general, the strength of the associations increased over time. Every relative risk was higher in the most recent period compared with earlier periods-some substantially increased (supplementary eTable 5).

\section{Change in partner and interpregnancy interval}

A change in partner means a change in half of the genetic contribution to the placenta and fetus, plus possible changes in residence or other aspects of the mother's environment, plus a generally longer interval between pregnancies. Eleven per cent of mothers changed partners between their first and second births. While the estimates are less precise owing to smaller numbers, results were similar for mothers with new partners. Adjusting for interpregnancy interval did not change the results (supplementary eTable 6).

\section{Restricting to a narrow definition of term births in first pregnancy}

When first term births were restricted to those in weeks 39-41 four of the relative risks were slightly attenuated and the fifth was strengthened (risk of preterm birth after term neonatal death; supplementary eTable 7).

\section{Discussion}

In this large, population based registry study, women with complications or poor outcomes in a first birth at term were at substantially increased risk of preterm 


\begin{tabular}{|c|c|c|c|c|}
\hline \multirow[b]{2}{*}{ First pregnancy (at term) } & \multicolumn{2}{|c|}{ PTB in second pregnancy } & \multicolumn{2}{|c|}{ PTB in second pregnancy (recurrences excludedt) } \\
\hline & No with PTB/No at risk (\%) & Relative risk $(95 \% \mathrm{Cl})$ & No with PTB/No at risk (\%) & Relative risk $(95 \% \mathrm{Cl})$ \\
\hline No complicationsł & $8202 / 265043(3.1)$ & Reference & - & - \\
\hline \multirow[b]{2}{*}{ Pre-eclampsia§ } & & & $7069 / 244496(2.9)$ & Reference \\
\hline & $688 / 11225(6.1)$ & $2.0(1.8$ to 2.1$)$ & $404 / 9696(4.2)$ & 1.4 (1.3 to 1.6$)$ \\
\hline \multirow[b]{2}{*}{ Placental abruption§ } & & & $7463 / 247527(3.0)$ & Reference \\
\hline & $41 / 562(7.3)$ & $2.3(1.7$ to 3.1$)$ & $35 / 547(6.4)$ & 2.1 (1.5 to 2.9$)$ \\
\hline \multirow[b]{2}{*}{ Stillbirth } & & & $7712 / 264247(2.9)$ & Reference \\
\hline & $72 / 551(13.1)$ & $4.2(3.4$ to 5.2$)$ & $69 / 548(12.6)$ & $4.3(3.5$ to 5.4$)$ \\
\hline \multirow[b]{2}{*}{ Neonatal death } & & & $7547 / 263945$ (2.9) & Reference \\
\hline & $22 / 219(10.0)$ & $3.2(2.2$ to 4.8$)$ & $22 / 218(10.1)$ & $3.5(2.4$ to 5.2$)$ \\
\hline \multirow[b]{2}{*}{ SGA 2.59} & & & $7994 / 259629$ (3.1) & Reference \\
\hline & $463 / 6939(6.7)$ & $2.2(2.0$ to 2.4$)$ & $426 / 5900(7.2)$ & $2.3(2.1$ to 2.6$)$ \\
\hline \multicolumn{5}{|c|}{$\begin{array}{l}\text { *Birth between } 20 \text { and } 36 \text { gestational weeks. } \\
\text { †Excludes both exposed and unexposed women with same complication in } 2 \text { nd pregnancy. Therefore, number at risk in reference group changes slightly } \\
\text { for each exposure. } \\
\text { \#For main analyses reference is term first pregnancies with none of the five complications. For analysis excluding recurrence of the same complication, } \\
\text { reference further excludes women with the complication of interest in the second pregnancy. } \\
\text { \$Reference category “No complications" for term pre-eclampsia and placental abruption is (number with PTB in } 2 \text { nd pregnancy/number at risk) } \\
7750 / 248214(3.1 \% \text { ) because the analytical period is restricted to } 1999-2014 \text { for these analyses. } \\
\text { १Small for gestational age (SGA) } 2.5 \text { th centile by each term gestational week (weeks } 44-46 \text { grouped). To avoid the possibility of data entry issues, term } \\
\text { births with infants with birth weight less than } 1000 \mathrm{~g} \text { were excluded }(n=5) \text { from analyses on term SGA, and preterm infants in second pregnancy with } \\
\text { birth weight } \leq 100 \mathrm{~g} \text { were excluded ( } \mathrm{n}=8 \text { ) }\end{array}$} \\
\hline
\end{tabular}

birth in a subsequent pregnancy. Term complications included pre-eclampsia, placental abruption, stillbirth, neonatal death, and small for gestational age. Relative risks for preterm birth were twofold to fourfold higher after these term complications. The presence of one term complication was associated with a twofold higher risk of subsequent preterm birth, whereas two or more complications were associated with a 3.5-fold higher risk. For comparison, the recurrence of preterm birth in this population was fivefold.

The largest increase in relative risk of preterm birth was seen for births in the very preterm period (weeks 28-30) (fig 3 and eTable 2). Similarly, the reverse analysis showed that early preterm birth (20-33 weeks) in the first pregnancy was most strongly associated with an increased risk of term complications in a subsequent pregnancy. These unadjusted results (table 2) support a hypothesis of shared pathways linking term complications and preterm birth. The consistent associations across a wide range of term complications suggest the presence of maternal specific factors that predispose them to these outcomes. Our adjustments for known demographic and lifestyle factors had little influence on these associations, pointing towards more fundamental shared conditions such as a maternal propensity to placental dysfunction. The likely presence of maternal specific factors is further supported by the persistence of the associations among women who change their partner between first and second pregnancies.

Our results from the most recent period (1999-2015) were consistently stronger than results from earlier periods. This might reflect changes over time in clinical practice. However, if medical interventions explained our observations of increased risk of preterm birth after term complications, we would expect to see a greater increased risk in gestational weeks 34-36. Instead, we found that risks were more strongly increased during earlier weeks of gestation. Furthermore, the observed increases in risk of preterm birth were seen with all modes of delivery; spontaneous as well as iatrogenic preterm birth.

\begin{tabular}{|c|c|c|c|c|}
\hline $\begin{array}{l}\text { Outcome in term } \\
\text { 1st pregnancy }\end{array}$ & $\begin{array}{l}\text { Crude relative } \\
\text { risk }(95 \% \mathrm{Cl})\end{array}$ & $\begin{array}{l}\text { Crude relative } \\
\text { risk }(95 \% \mathrm{Cl})\end{array}$ & $\begin{array}{l}\text { Adjusted relative } \\
\text { risk }(95 \% \mathrm{Cl})\end{array}$ & $\begin{array}{l}\text { Adjusted relative } \\
\text { risk }(95 \% \mathrm{Cl})\end{array}$ \\
\hline No complications & 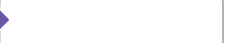 & 1 (reference) & & 1 (reference) \\
\hline Pre-eclampsia & $\bullet$ & 1.96 (1.82 to 2.12$)$ & $\diamond$ & 1.97 (1.82 to 2.12$)$ \\
\hline Placental abruption & $\longrightarrow-$ & 2.34 (1.74 to 3.14$)$ & $\infty$ & 2.25 (1.68 to 3.02$)$ \\
\hline Stillbirth & $\rightarrow$ & 4.22 (3.40 to 5.24$)$ & $\leadsto$ & 4.21 (3.39 to 5.22$)$ \\
\hline Neonatal death & $\longrightarrow-$ & 3.25 (2.18 to 4.83$)$ & $\infty$ & 3.18 (2.15 to 4.70$)$ \\
\hline \multirow[t]{2}{*}{ SGA } & $\diamond$ & 2.16 (1.97 to 2.36$)$ & $\diamond$ & 2.04 (1.86 to 2.24 ) \\
\hline & $\begin{array}{llll}2 & 3 & 4 & 5\end{array}$ & & $\begin{array}{lll}3 & 4 & 5\end{array}$ & \\
\hline
\end{tabular}

Fig 2 | Unadjusted (filled diamonds) and adjusted (open diamonds) relative risks for preterm birth in second pregnancy by complications in first pregnancy at term, Norway, 1999-2015. Reference is term birth in first pregnancy without any of the five complications. Analyses are adjusted for maternal age, year of birth for first child, and maternal education. Supplementary eTable 1 presents adjusted relative risks ( $95 \%$ confidence intervals) with further adjustments. SGA=small for gestational age 


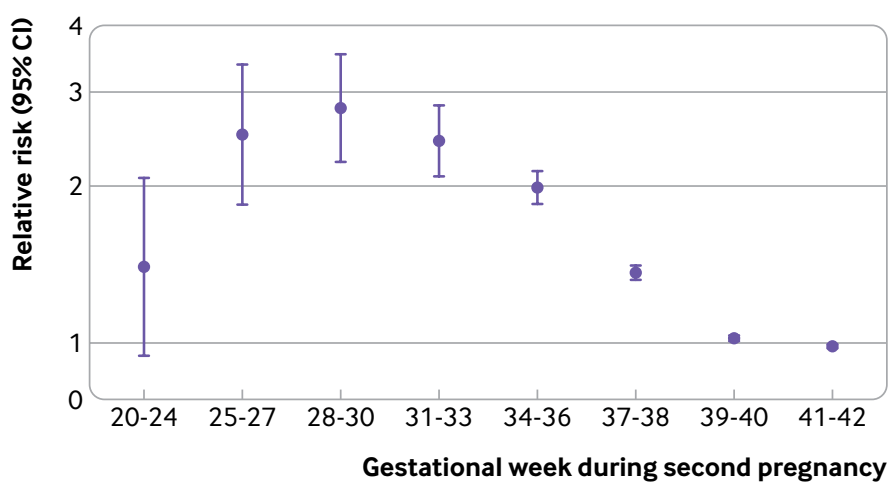

Fig 3 | Relative risks (95\% confidence intervals) for birth in specific gestational weeks in second pregnancy for women with any term complications in first pregnancy, Norway 1999-2015. Exposure is any term complication (one or more of five complications). Reference is term birth in first pregnancy without any of the five complications. Because pre-eclampsia and placental abruption are included in the "Any complication" category, analysis is restricted to 1999-2014. Denominators are all fetuses in utero at the beginning of the specific week interval. With $100 \%$ of births occurring in the final interval ( $\geq 43$ weeks), no estimates were calculated for these last gestational weeks. Filled circles represent unadjusted relative risks for birth in specific gestational weeks in the second pregnancy "ischaemic placental disease." 9 A mother's risk of future cardiovascular disease might also relate to these shared pathways linking the five complications and preterm birth. ${ }^{29}$

\section{Comparison with other studies}

Various sensitivity analyses produced no meaningful differences in the results. Given this robustness, it might seem surprising that these observations did not emerge earlier. A few suggestions of such associations are found throughout the literature, specifically for pre-eclampsia and stillbirths. For the other outcomes we could find no comparable literature.

Pre-eclampsia is the only complication for which we have found similar findings to ours in the literaturealthough even here, the studies are few. Most studies investigating pre-eclampsia and subsequent preterm birth have not focused on pre-eclampsia among term births. ${ }^{14} 30$ A study that did (a Swedish study from 1992 to 2006) did not find an association between pre-eclampsia in a first pregnancy at term and later spontaneous preterm birth. ${ }^{15}$ However, the researchers' different criteria for the exposure and reference groups make it difficult to compare their study with our study. We found that the associations strengthened over time (supplementary eTable 5) and the relative risk for preterm birth was still increased when restricting to a second spontaneous preterm birth (supplementary eTable 4). One study considered the reverse association with pre-eclampsia. Rasmussen et al reported that preterm birth in a first pregnancy was associated with an increased risk of term pre-eclampsia in the second pregnancy. ${ }^{31}$ Another Norwegian study assessed the reverse association of stillbirth in a pregnancy at term after a previous preterm birth, again with results similar to ours. $^{32}$

We have found no studies that looked at other complications at term and risk of later preterm birth. For example, a recent systematic review produced a pooled odds ratio of 2.8 (95\% confidence interval 2.3 to 3.5) for preterm birth after stillbirth, but the analysis did not consider term stillbirths separately from preterm stillbirths. ${ }^{33}$

\begin{tabular}{|c|c|c|c|c|c|c|c|c|c|c|}
\hline \multirow[b]{3}{*}{$\begin{array}{l}\text { First } \\
\text { pregnancy }\end{array}$} & \multicolumn{10}{|c|}{ Second pregnancy (No (\%) with complication/No (\%) at risk) } \\
\hline & \multicolumn{2}{|c|}{ Term pre-eclampsia } & \multicolumn{2}{|c|}{ Term placental abruption } & \multicolumn{2}{|c|}{ Term stillbirth } & \multicolumn{2}{|c|}{ Term neonatal death* } & \multicolumn{2}{|c|}{ Term SGA $2.5 \neq$} \\
\hline & Pre-eclampsiat & $\begin{array}{l}\text { Relative risk } \\
(95 \% \mathrm{Cl})\end{array}$ & $\begin{array}{l}\text { Placental } \\
\text { abruptiont }\end{array}$ & $\begin{array}{l}\text { Relative risk } \\
(95 \% \mathrm{Cl})\end{array}$ & Stillbirth & $\begin{array}{l}\text { Relative risk } \\
(95 \% \mathrm{Cl})\end{array}$ & $\begin{array}{l}\text { Neonatal } \\
\text { death }\end{array}$ & $\begin{array}{l}\text { Relative risk } \\
(95 \% \mathrm{Cl})\end{array}$ & SGA 2.5 & $\begin{array}{l}\text { Relative risk } \\
(95 \% \mathrm{Cl})\end{array}$ \\
\hline Term & $\begin{array}{l}3149 / 246926 \\
(1.3)\end{array}$ & Reference & $\begin{array}{l}446 / 256942 \\
(0.2)\end{array}$ & Reference & $\begin{array}{l}341 / 274327 \\
(0.1)\end{array}$ & Reference & $\begin{array}{l}149 / 273789 \\
(0.05)\end{array}$ & Reference & $\begin{array}{l}5467 / 268324 \\
(2.0)\end{array}$ & Reference \\
\hline All preterm & $\begin{array}{l}349 / 11353 \\
(3.1)\end{array}$ & $\begin{array}{l}2.4 \\
(2.2 \text { to } 2.7)\end{array}$ & $\begin{array}{l}45 / 13416 \\
(0.3)\end{array}$ & $\begin{array}{l}1.9 \\
(1.4 \text { to } 2.6)\end{array}$ & $\begin{array}{l}17 / 13942 \\
(0.1)\end{array}$ & $\begin{array}{l}0.98 \\
(0.6 \text { to } 1.6)\end{array}$ & $(0.07) \S$ & $\begin{array}{l}1.3 \\
(0.7 \text { to } 2.6)\end{array}$ & $\begin{array}{l}551 / 14336 \\
(3.8)\end{array}$ & $\begin{array}{l}1.9 \\
(1.7 \text { to } 2.1)\end{array}$ \\
\hline 20-33 weeks & $\begin{array}{l}99 / 2893 \\
(3.4)\end{array}$ & $\begin{array}{l}2.7 \\
(2.2 \text { to } 3.3 \text { ) }\end{array}$ & $\begin{array}{l}19 / 3599 \\
(0.5)\end{array}$ & $\begin{array}{l}3.0 \\
(1.9 \text { to } 4.8)\end{array}$ & $(0.2) \S$ & $\begin{array}{l}1.6 \\
(0.8 \text { to } 3.5)\end{array}$ & $(0.2) \S$ & $\begin{array}{l}4.0 \\
(1.9 \text { to } 8.5)\end{array}$ & $\begin{array}{l}206 / 3961 \\
(5.2)\end{array}$ & $\begin{array}{l}2.6 \\
(2.2 \text { to } 2.9)\end{array}$ \\
\hline 34-36 weeks & $\begin{array}{l}250 / 8460 \\
(3.0)\end{array}$ & $\begin{array}{l}2.3 \\
(2.0 \text { to } 2.6)\end{array}$ & $\begin{array}{l}26 / 9817 \\
(0.3)\end{array}$ & $\begin{array}{l}1.5 \\
\text { (1.03 to } 2.3 \text { ) }\end{array}$ & $(0.1) \S$ & $\begin{array}{l}0.8 \\
(0.4 \text { to } 1.4)\end{array}$ & $(0.03) \S$ & $\begin{array}{l}0.5 \\
(0.2 \text { to } 1.7)\end{array}$ & $\begin{array}{l}345 / 10375 \\
(3.3)\end{array}$ & $\begin{array}{l}1.6 \\
(1.5 \text { to } 1.8)\end{array}$ \\
\hline $\begin{array}{l}\text { SGA } 2.5=\text { small f } \mathrm{fo} \\
\text { *Study period re } \\
\text { +Pregnancies en } \\
\text { †To avoid data e }\end{array}$ & or gestational age 2.5 & th centile. & & ith term preg & 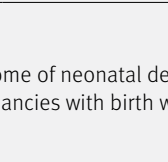 & ก. & 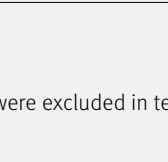 & 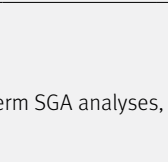 & 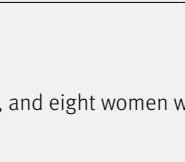 & preterm \\
\hline
\end{tabular}




\section{Strengths and limitations of this study}

Outcomes and exposures for this analysis rely on data from the Medical Birth Registry of Norway, with inevitable misclassification. In particular, more women are estimated to have pre-eclampsia than are recorded in the birth registry. ${ }^{27}$ To the extent that women in our comparison group have unrecorded complications, our main results might be biased towards the null.

Strengths of the study include population based birth data, linking each mother with all her pregnancies. Prospectively recorded events minimise recall bias. The large dataset makes it possible to study relatively rare outcomes with precision. By restricting our analysis to first and second births, we limited the influence of selection, since $80 \%$ of women in Norway continue to a second pregnancy. At the same time, our restriction to this relatively unselected group of women makes it more difficult to extrapolate to third or later pregnancies.

Our findings are based on women in a country with universal free and accessible healthcare. The relatively homogeneous Norwegian population and its strong public support systems might limit the generalisability of these findings. Notably, although the preterm birth rate is around $6 \%$ in Norway, the corresponding rate is close to $9 \%$ in the rest of Europe and close to $10 \%$ in the United States. ${ }^{34}$ In a more heterogeneous population with greater income and health disparities the shared factors resulting in poor outcomes across pregnancies would presumably include a wider array of structural and social causes, with less opportunity to observe underlying biological propensities.

\section{Conclusions}

Serious complications in pregnancy at term imply an increased risk not only of recurrence of the same outcome but also of preterm birth in a subsequent pregnancy. These findings might inform antenatal clinical care by helping to identify women at increased risk of preterm delivery. Further exploration of the causal factors underlying these shared risks might provide insight into fundamental biological mechanisms that link a broad range of pregnancy complications.

We thank Cande Ananth (Rutgers, State University of New Jersey) for his help in bringing relevant literature to our attention, Jannicke Igland (University of Bergen) for assistance with statistics and graphs, and Donna Baird and Clarice Weinberg (National Institute of Environmental Health Sciences, Durham, NC) who provided useful comments on earlier versions of this manuscript.

Contributors: LGK, AJW, RS, and QEH conceived and designed the study. RS obtained access to data. LGK conducted the data analysis and drafted the initial version of the manuscript. AJW, RS, TØ, and QEH provided important insight during the data analysis. All authors contributed in the interpretation of the data and critically revised the manuscript. All authors had full access to tables and figures in the study and can take responsibility for the integrity of the data and the accuracy of the data analysis. LGK is the guarantor. The corresponding author attests that all listed authors meet authorship criteria and that no others meeting the criteria have been omitted.

Funding: This research was supported in part by the Intramural Research Program of the National Institutes of Health, National Institute of Environmental Health Sciences, by the European Research Council under the European Union's Horizon 2020 Research and Innovation Programme (ERC advanced grant 2018, agreement No
833076), by the National Research School in Population Based Epidemiology (EPINOR for PhD candidates in Norway), and by the US Norway Fulbright Foundation for Educational Exchange. The funders had no role in considering the study design or in the collection, analysis, interpretation of data, writing of the report, or decision to submit the article for publication. The authors have no financial interests that might pose a conflict of interests in connection with this work.

Competing interests: All authors have completed the ICME uniform disclosure form at www.icmje.org/coi_disclosure.pdf and declare: LGK reports grants from the US-Norway Fulbright Foundation for Educational Exchange, during the conduct of the study; no financial relationships with any organisations that might have an interest in the submitted work in the previous three years; no other relationships or activities that could appear to have influenced the submitted work.

Ethical approval: This study was approved by the regional ethics committee in Norway (2015/1728), with an exemption from written informed consent.

Data sharing: No additional data available.

The lead author (LGK) affirms that the manuscript is an honest, accurate, and transparent account of the study being reported. No important aspects of the study have been omitted, and any discrepancies from the study as originally planned have been explained.

Dissemination to participants and related patient and public communities: A summary of the results will be sent to the Norwegian newsletter Fødselsnytt published by the Norwegian Institute of Public Health, which is distributed to maternity wards and hospitals and children's ward throughout Norway.

This is an Open Access article distributed in accordance with the Creative Commons Attribution Non Commercial (CC BY-NC 4.0) license, which permits others to distribute, remix, adapt, build upon this work non-commercially, and license their derivative works on different terms, provided the original work is properly cited and the use is noncommercial. See: http://creativecommons.org/licenses/by-nc/4.0/.

1 Phillips C, Velji Z, Hanly C, Metcalfe A. Risk of recurrent spontaneous preterm birth: a systematic review and meta-analysis. BMJ Open 2017;7:e015402. doi:10.1136/bmjopen-2016-015402

2 Melve KK, Skjaerven R, Gjessing HK, Oyen N. Recurrence of gestational age in sibships: implications for perinatal mortality. Am J Epidemiol 1999;150:756-62. doi:10.1093/oxfordjournals.aje. $\mathrm{a} 010078$

3 Ananth CV, Vintzileos AM. Epidemiology of preterm birth and its clinical subtypes. J Matern Fetal Neonatal Med 2006;19:773-82. doi:10.1080/14767050600965882

4 Hutcheon JA, Platt RW. The missing data problem in birth weight percentiles and thresholds for "small-for-gestational-age". Am J Epidemiol 2008;167:786-92. doi:10.1093/aje/kwm327

5 Gjessing HK, Grøttum P, Økland I, Eik-Nes SH. Fetal size monitoring and birth-weight prediction: a new population-based approach. Ultrasound Obstet Gynecol 2017;49:500-7. doi:10.1002/ uog. 15954

6 Di Renzo GC. The great obstetrical syndromes. I Matern Fetal Neonatal Med 2009:22:633-5. doi:10.1080/14767050902866804

7 Romero R. Prenatal medicine: the child is the father of the man. 1996. J Matern Fetal Neonatal Med 2009;22:636-9. doi:10.1080/14767050902784171

8 Brosens I, Pijnenborg R, Vercruysse L, Romero R. The "Great Obstetrical Syndromes" are associated with disorders of deep placentation. Am / Obstet Gynecol 2011;204:193-201. doi:10.1016/j.ajog.2010.08.009

9 Ananth CV. Ischemic placental disease: a unifying concept for preeclampsia, intrauterine growth restriction, and placental abruption. Semin Perinatol 2014;38:131-2. doi:10.1053/i. semperi.2014.03.001

10 Ananth CV, Peltier MR, Chavez MR, Kirby RS, Getahun D, Vintzileos AM. Recurrence of ischemic placental disease. Obstet Gynecol 2007;110:128-33. doi:10.1097/01. AOG.0000266983.77458.71

11 Parker SE, Werler MM. Epidemiology of ischemic placental disease: a focus on preterm gestations. Semin Perinatol 2014;38:133-8. doi:10.1053/j.semperi.2014.03.004

12 Parker SE, Werler MM, Gissler M, Tikkanen M, Ananth CV. Placental abruption and subsequent risk of pre-eclampsia: a population-based case-control study. Paediatr Perinat Epidemiol 2015;29:211-9. doi:10.1111/ppe.12184

13 Ananth CV, Smulian JC, Vintzileos AM. Ischemic placental disease: maternal versus fetal clinical presentations by gestational age. J Matern Fetal Neonatal Med 2010;23:887-93. doi:10.3109/14767050903334885 
14 Lain KY, Krohn MA, Roberts JM. Second pregnancy outcomes following preeclampsia in a first pregnancy. Hypertens Pregnancy 2005;24:159-69. doi:10.1081/PRG-200059869

15 Wikström AK, Stephansson O, Cnattingius S. Previous preeclampsia and risks of adverse outcomes in subsequent nonpreeclamptic pregnancies. Am / Obstet Gynecol 2011:204:148.e1-6. doi:10.1016/j.ajog.2010.09.003

16 Committee on Practice Bulletins-Obstetrics, The American College of Obstetricians and Gynecologists. Practice bulletin no. 130: prediction and prevention of preterm birth. Obstet Gynecol 2012;120:964-73. doi:10.1097/AOG.0b013e3182723b1b

17 FIGO Working Group on Good Clinical Practice in Maternal-Fetal Medicine. Good clinical practice advice: Prediction of preterm labor and preterm premature rupture of membranes. Int J Gynaecol Obstet 2019;144:340-6. doi:10.1002/ijgo.12744

18 National Collaborating Centre for Women's and Children's Health (UK). National Institute for Health and Care Excellence: Clinical Guidelines. Preterm Labour and Birth, 2015.

19 The Norwegian Society for Gynecology and Obstetrics. Guidelines in obstetrics. [In Norwegian]. https://www.legeforeningen.no/ foreningsledd/fagmed/norsk-gynekologisk-forening/veiledere/

20 Irgens LM. The Medical Birth Registry of Norway. Epidemiological research and surveillance throughout 30 years. Acta Obstet Gynecol Scand 2000;79:435-9. doi:10.1080/j.16000412.2000.079006435.x

21 Skjaerven R, Gjessing HK, Bakketeig LS. Birthweight by gestational age in Norway. Acta Obstet Gynecol Scand 2000;79:440-9. doi:10.1080/j.1600-0412.2000.079006440.x

22 Hoyert DL, Gregory EC. Cause of fetal death: data From the Fetal Death Report, 2014. Natl Vital Stat Rep 2016;65:1-25.

23 Melve KK, Skjaerven R, Rasmussen S, Irgens LM. Recurrence of stillbirth in sibships: Population-based cohort study. Am J Epidemiol 2010;172:1123-30. doi:10.1093/aje/kwq259

24 Klungsøyr K, Morken NH, Irgens L, Vollset SE, Skjaerven R. Secular trends in the epidemiology of pre-eclampsia throughout 40 years in Norway: prevalence, risk factors and perinatal survival. Paediatr Perinat Epidemiol 2012;26:190-8. doi:10.1111/j.13653016.2012.01260.x

25 Rasmussen S, Irgens LM, Dalaker K. The effect on the likelihood of further pregnancy of placental abruption and the rate of its recurrence. Br J Obstet Gynaecol 1997;104:1292-5. doi:10.1111/j.1471-0528.1997.tb10977.x

26 Bakketeig LS, Bjerkedal T, Hoffman HJ. Small-for-gestational age births in successive pregnancy outcomes: results from a longitudinal study of births in Norway. Early Hum Dev 1986;14:187-200. doi:10.1016/0378-3782(86)90180-5

27 Klungsøyr K, Harmon QE, Skard LB, et al. Validity of pre-eclampsia registration in the medical birth registry of norway for women participating in the norwegian mother and child cohort study, 19992010. Paediatr Perinat Epidemiol 2014;28:362-71. doi:10.1111/ ppe. 12138

28 Sorbye LM, Skjaerven R, Klungsoyr K, Morken NH. Gestational diabetes mellitus and interpregnancy weight change: A populationbased cohort study. PLoS Med 2017;14:e1002367. doi:10.1371/ journal.pmed.1002367

29 Grandi SM, Filion KB, Yoon S, et al. Cardiovascular disease-related morbidity and mortality in women with a history of pregnancy complications. Circulation 2019;139:1069-79. doi:10.1161/ CIRCULATIONAHA.118.036748

30 Koike T, Minakami H, Izumi A, Watanabe T, Matsubara S, Sato I. Recurrence risk of preterm birth due to preeclampsia. Gynecol Obste Invest 2002;53:22-7. doi:10.1159/000049406

31 Rasmussen S, Ebbing C, Irgens LM. Predicting preeclampsia from a history of preterm birth. PLOS One 2017;12:e0181016. doi:10.1371/journal.pone.0181016

32 Rasmussen S, Irgens LM, Skjaerven R, Melve KK. Prior adverse pregnancy outcome and the risk of stillbirth. Obstet Gynecol 2009;114:1259-70. doi:10.1097/ AOG.0b013e3181c22422

33 Malacova E, Regan A, Nassar N, et al. Risk of stillbirth, preterm delivery, and fetal growth restriction following exposure in a previous birth: systematic review and meta-analysis. BJOG 2018;125:183-92. doi:10.1111/1471-0528.14906

34 Chawanpaiboon S, Vogel JP, Moller AB, et al. Global, regional, and national estimates of levels of preterm birth in 2014: a systematic review and modelling analysis. Lancet Glob Health 2019;7:e37-46. doi:10.1016/S2214-109X(18)30451-0

Web appendix: Supplemental material 